\title{
Parietal wall endometriosis: a rare case report
}

\author{
Mahija Sahu', Umesh Ray ${ }^{2}$, Bhabani Sankar Nayak ${ }^{1} *$ \\ ${ }^{1}$ Department of Obstetrics \& Gynaecology, SCB Medical College Hospital, Cuttack, Odisha, India \\ ${ }^{2}$ Department of Surgery, City Hospital, Cuttack, Odisha, India
}

Received: 19 February 2015

Accepted: 01 March 2015

\section{*Correspondence:}

Dr. Bhabani Sankar Nayak,

E-mail: bhabanivss@gmail.com

Copyright: ( $\odot$ the author(s), publisher and licensee Medip Academy. This is an open-access article distributed under the terms of the Creative Commons Attribution Non-Commercial License, which permits unrestricted non-commercial use, distribution, and reproduction in any medium, provided the original work is properly cited.

\begin{abstract}
A 28 year old P2L1 with one previous cesarean presented with cyclical pain in periumblical area just below umbilicus for 1 year with USG finding suggestive of parietal wall endometriosis planned for surgery on her $2^{\text {nd }}$ day of menstruation. She underwent diagnostic laparoscopy with complete excision of endometrioma. Diagnostic laparoscopy showed no evidence of endometrioma in the pelvic cavity except for omental adhesion at parietal wall endometrioma site, adhesiolysis of omentum, mesh repair of rectus sheath defect done. She is followed up for last 3 cycles post-operative and has no cyclical pain further.
\end{abstract}

Keywords: Cyclical pain, Parietal wall endometriosis, Complete excision

\section{INTRODUCTION}

Endometriosis is a pathological feature induced by the active development of islets of endometrial cells at ectopic site. The most common site of occurrence is the genital system, causing specific gynecological pathology. The extragenital localization of endometriosis is rare, but it is more severe and it may have a malignant local evolution, although its structures remain benign. The endometrial inclusions in the abdominal wall scar are iatrogenic "implants", created at the same time with the surgical operation, performed on patients with genital endometriosis. But very very rarely it is seen in the parietal wall of abdomen. The only curable treatment of this topography of endometriosis is the surgical removal of all the pathological tissue, through a large excision. The hormonal therapy is adjuvant.

\section{CASE REPORT}

28 year old P2L1 with 1 previous LSCS presented with dull aching pain periumblical area just below umbilicus with cyclical exacerbation during menses for past 1 year. Her LMP was on 17.9.14 with regular cycles. She was P2L1 with $1^{\text {st }}$ child 9 years old, VD and $2^{\text {nd }}$ one delivered by LSCS 5 years back in 2009 who died after 1 day of delivery. No suggestive past history.

All the routine investigations were done and found to be within normal limits. USG finding showed collection below rectus sheath of size $5 \times 5 \mathrm{~cm}$ of mixed echogenic nature suggestive of parietal wall collection endometriosis. She underwent FNAC which was inconclusive. She was planned for surgery during her $2^{\text {nd }}$ day of menses.

She underwent diagnostic laparoscopy with adhesiolysis with excision of endometrioma under general anesthesia on 19.10.2014. Diagnostic laparoscopy showed no evidence of pelvic or extrapelvic endometriosis. There was adherence of omentum to the peritoneal wall in the infraumblical area at the site of parietal endometrioma, adhesiolysis done. A midline vertical incision of $6-7 \mathrm{~cm}$ below umbilicus was given. The endometrioma of size $5 \times 5$ was below rectus sheath and was adherent to it and extending upto rectus muscle. Endometrioma was excised and sent for HP study. There was no intra-peritoneal extension and peritoneum was not opened. Mesh repair of rectus sheath defect done, a surgical vacuum drain given. On $3^{\text {rd }}$ post-op day drain was removed and dressing was 
done, on $10^{\text {th }}$ post-op day stitches were removed and wound was healthy. The histopathology was suggestive of endometriosis of parietal wall. She is being followed up for last three months following surgery. She is relieved of her pain and wound is healthy.

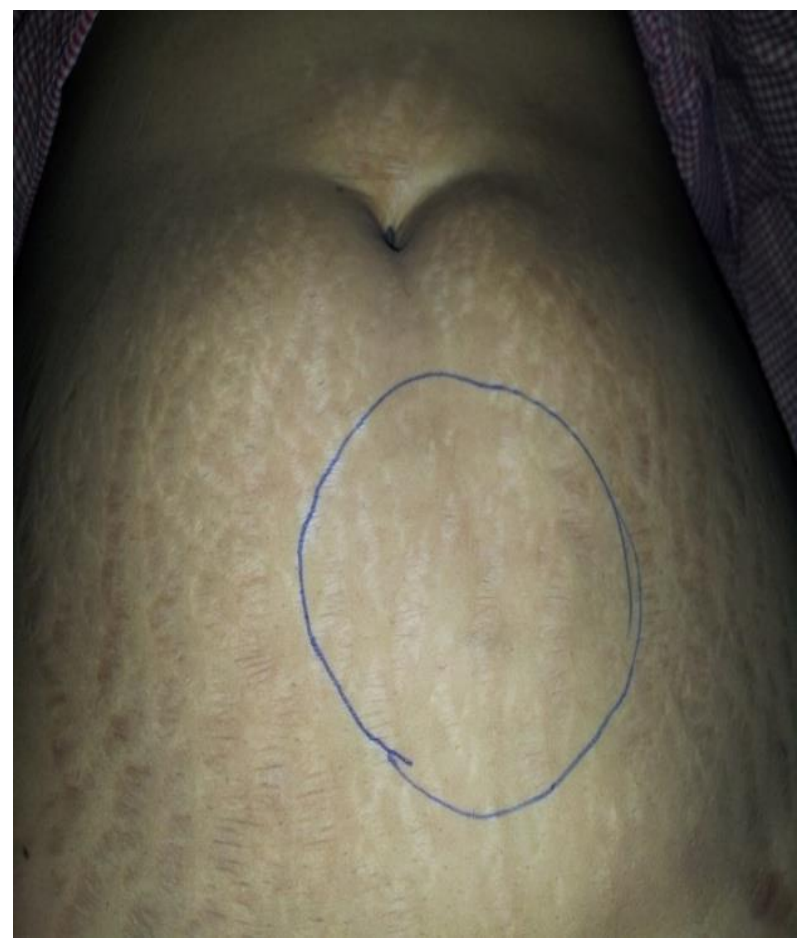

Figure 1: Skin marking showing the area of endometriosis.

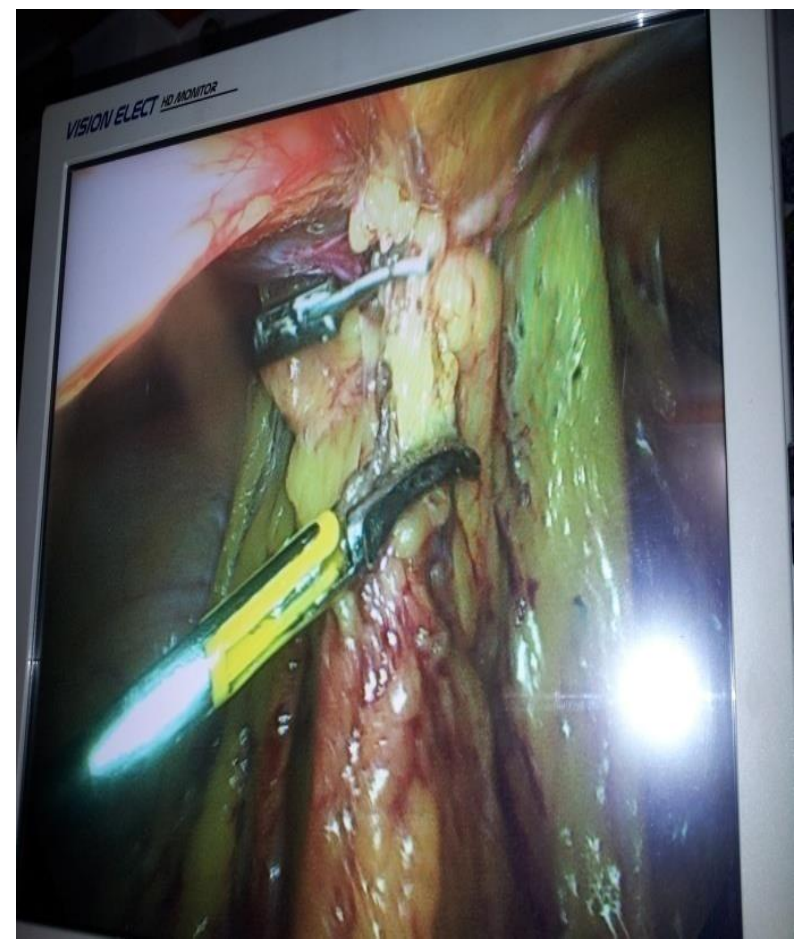

Figure 2: Laparoscopic finding of infraperitoneal adhesions of omentum to endometriotic site.

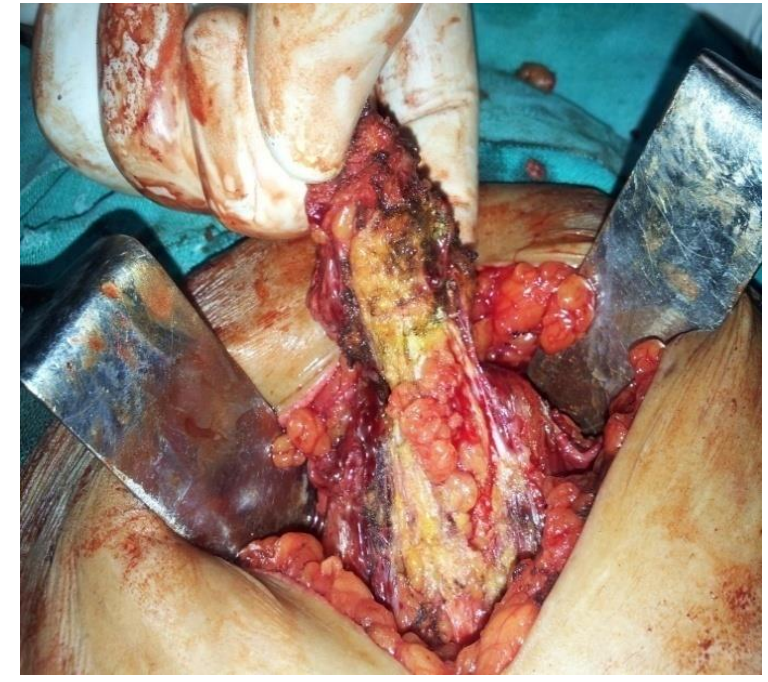

Figure 3: Vertical incision on the abdominal wall and enucleation of endometrioma.

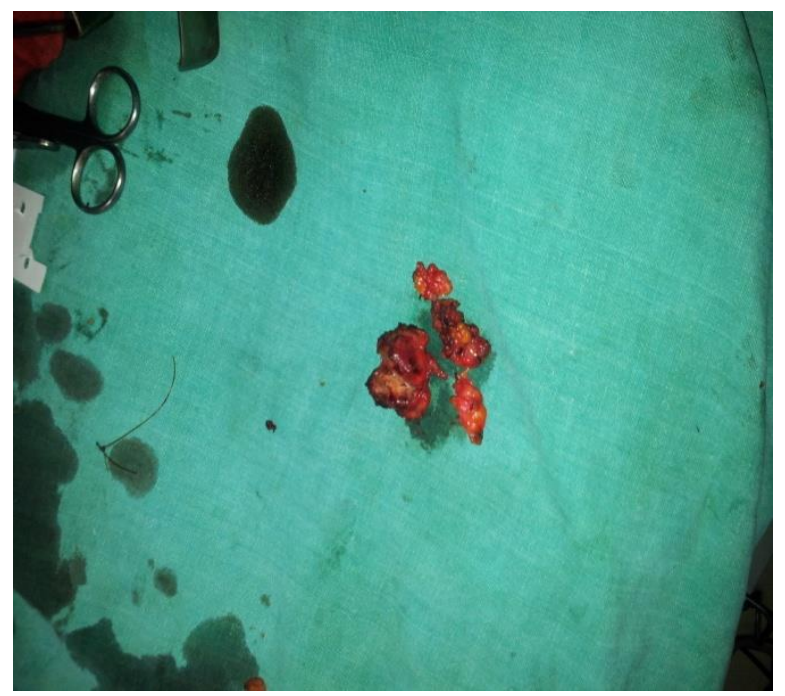

Figure 4: Specimen after removal.

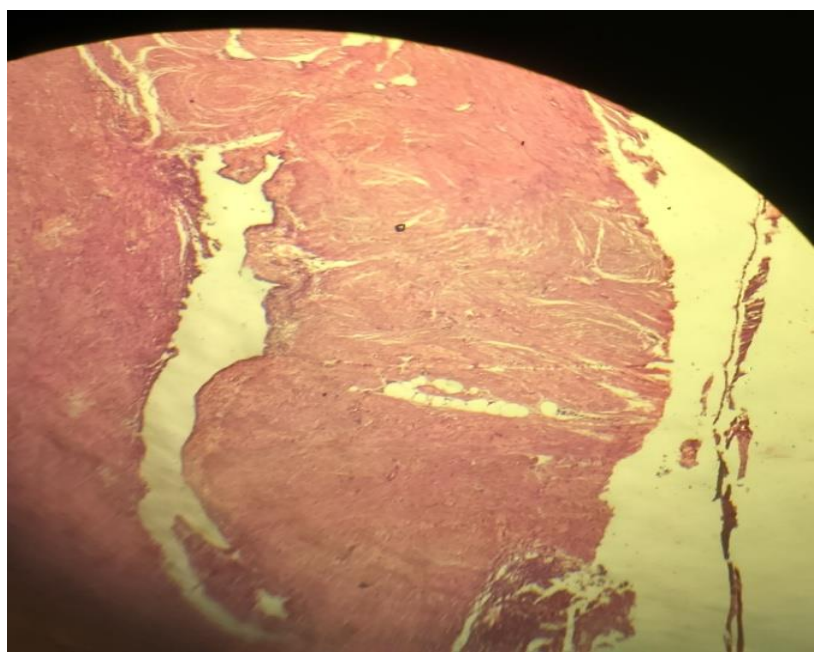

Figure 5: Histopathology suggestive of parietal wall endometriosis. 


\section{DISCUSSION}

The cause of endometriosis has remained controversial with many theories. However, scar endometriosis, especially those occurring after surgeries involving the uterus like hysterectomy, caesarean section, myomectomy etc. have supported the mechanical transplantation theory. In such cases, it is believed that endometrium is iatrogenically transplanted to the surgical scar. ${ }^{1}$

In our case report, the patient had a history of caesarean section but was not known to have pre-existing endometriosis.

Endometrial implants in the abdominal wall could be considered a long term, collateral but preventable effect of gynecological procedures. The late onset of symptoms after surgery is the usual reason for misdiagnosis. Review of the gynecologic literature indicates that the presentation of patients with caesarean section scar endometriosis is made easily on clinical grounds. ${ }^{2,3}$ Classically, the scenario is that of a parous woman complaining of a painful nodule, varying with menses, at the incision site.

Conversely, review of the surgical literature indicates that preoperative diagnosis is often incorrect. ${ }^{4,5}$ But in our case cyclical pain typically helps to diagnose as a case of endometriosis. The mean period between procedure and start of symptoms has been reported to be between 4.5 years to 5.72 years in various literatures. ${ }^{6,7}$ However some series report it as early as three months and even after ten years. ${ }^{8}$ In our case it is five years.

A high index of suspicion is recommended when a woman presents with postoperative abdominal lump. Surgical excision provides both diagnostic and therapeutic intervention. Once the diagnosis is made on clinical grounds. Wide surgical excision and confirmation of the diagnosis by histopathologic examination of the excised tissue should be done. However, whenever the diagnosis is uncertain, efforts should be made to make a preoperative diagnosis with the help of imaging techniques and FNAC.
Malignant change of endometriosis in a cesarean scar is rare, however has been reported. ${ }^{9}$ Long standing recurrent scar could undergo malignant change and clinicians should be aware.

\section{Funding: No funding sources \\ Conflict of interest: None declared \\ Ethical approval: Not required}

\section{REFERENCES}

1. Lahiri AK, Sharma K, Busiri N. Endometriosis of the uterine casarean section scar: a case report. Indian $\mathbf{J}$ Radiol Imaging. 2008;18:66-8.

2. Pathan SK, Kapila K, Haji BE, Mallik MK, AlAnsary TA, George SS, et al. Cytomorphological spectrum in scar endometriosis: a study of eight cases. Cytopathology. 2005 Apr;16(2):94-9.

3. Taff L, Jones SJ. Cesarean scar endometriosis: a report of two cases. J Reprod Med. 2002;47(1):50-2.

4. Thapa A, Kumar A, Gupta S. Abdominal wall endometriosis: Report of a case and how much we know about it. Internet J Surg. 2007;9(2):1-2.

5. Goel P, Sood SS, Dalal A. Cesarean scar endometriosis- Report of two cases. Indian J Med Sci. 2005;59:495-8.

6. Gunes M, Kayikcioglu F, Ozturkoglu E, Haberal A. Incisional endometriosis after cesarean section, episiotomy and other gynecologic procedures. J Obstet Gynecol Res. 2005 Oct;31(5):471-5.

7. Dragoumis K, Mikos T, Zafrakas M, Assimakopoulos E, Stamatopoulos P. Endometriotic uterocutaneous fistula after cesarean section. Gynecol Obstet Invest. 2004;57:90-2.

8. Celik M, Bulbuloglu E, Buyukbese MA, Cetinkaya A. Abdominal wall endometrioma: localizing in rectus abdominus sheath. Turk J Med Sci. 2004;34:341-3.

9. Alberto VO, Lynch M, Labbei FN, Jeffers M. Primary abdominal wall clear cell carcinoma arising in a cesarean section scar endometriosis. Ir J Med Sci. 2006;175(1):69-71.

DOI: $10.5455 / 2320-1770 . i j r \operatorname{cog} 20150454$

Cite this article as: Sahu M, Ray U, Nayak BS.

Parietal wall endometriosis: a rare case report. Int J Reprod Contracept Obstet Gynecol 2015;4:524-6. 